\title{
Alteration of Histone H3 Lysine 4 Trimethylation on Putative Lytic Gene Promoters by Human Set1 Complex during Reactivation of Kaposi's Sarcoma-Associated Herpesvirus
}

\author{
Jae Eun Jong Seho Cha Jun Hyeong Jang Taegun Seo \\ Department of Life Science, Dongguk University-Seoul, Seoul, South Korea
}

\author{
Key Words \\ Histone modification • Histone $\mathrm{H} 3$ lysine 4 trimethylation • \\ Human Set1 complex · Kaposi's sarcoma-associated \\ herpesvirus • Viral life cycles
}

\begin{abstract}
Objective: Histone $\mathrm{H} 3$ lysine 4 is trimethylated by the human Set1 complex, which regulates the activation of gene expression. The aim of this study was to identify whether the levels of histone $\mathrm{H} 3$ lysine 4 trimethylation ( $\mathrm{H} 3 \mathrm{~K} 4 \mathrm{me} 3)$ and the recruitment of human Set1 complex at the promoter regions of lytic genes quantitatively change during reactivation from latent to lytic infection of Kaposi's sarcoma-association herpesvirus (KSHV). Methods: During KSHV reactivation, global changes of H3K4 methylation in KSHV-infected cells were analyzed by Western blot. The relative levels of association between proteins and promoter regions were determined by chromatin immunoprecipitation assay and quantitative real-time PCR using specific antibodies and primer sets. $\boldsymbol{R} \boldsymbol{e}$ sults: Our results showed that KSHV reactivation does not alter the overall cellular levels of H3K4 methylation. We observed that the switch from latency to lytic cycle leads to upregulation of $\mathrm{H} 3 \mathrm{~K} 4 \mathrm{me} 3$ at the active lytic genes. We also found that the recruitment of RNA pol II and subunits of human Set1 complex were enriched at the same regions in response to KSHV reactivation. Conclusion: These results
\end{abstract}

demonstrate that the increase of H3K4me3 by human Set1 complex is involved in activation of lytic genes during the lytic infection of KSHV.

Copyright $\odot 2013$ S. Karger AG, Base

\section{Introduction}

Histones associate with DNA to form the nucleosomes which contain an octamer consisting of two copies each of core histone proteins $\mathrm{H} 2 \mathrm{~A}, \mathrm{H} 2 \mathrm{~B}, \mathrm{H} 3$, and $\mathrm{H} 4$, and a short length of DNA wrapped around it [1]. Histones are covalently modified by a specific modification enzyme complex. Since N-terminal tails of histones are exposed to the extranucleosomal space, they are commonly subject to various posttranslational modifications [2]. These posttranslational modifications include methylation, acetylation, phosphorylation, ubiquitination, sumoylation, biotinylation, and ADP-ribosylation. Histone modifications change the chromatin structure and the accessibility of transcription factors to their target sites by affecting interactions between histones and DNA. This ultimately mediates the epigenetic regulation of gene expression and leads to a distinct biological output [3-6]. Histone residues that can be modified are highly conserved in eukaryotes. Histone $\mathrm{H} 3$ lysines are the best understood of the residues that are important for regulation

\section{KARGER}

Fax +4161306 1234

E-Mail karger@karger.ch

www.karger.com
(C) 2013 S. Karger AG, Basel

0300-5526/13/0562-0091\$38.00/0

Accessible online at:

www.karger.com/int
Taegun Seo, $\mathrm{PhD}$

Department of Life Science

Dongguk University-Seoul, 26, 3 Pil-dong, Jung-gu

Seoul 100-715 (Korea)

E-Mail tseo@dongguk.edu 
of gene expression by epigenetic modification, including methylation and acetylation [7]. Methylated lysine of histone $\mathrm{H} 3$ modulates the transcription both positively and negatively. The effects of methylation of histone $\mathrm{H} 3$ at lysine 4 (H3K4) on chromatin functions depend on methylation status (mono-, di-, trimethylation). Trimethylation of H3K4 (H3K4me3) may serve as a marker of actively transcribed genes because it is generally involved in transcriptional activation $[8,9]$. H3K4me3 is deposited by Set1, histone methyltransferase. In yeast, $\mathrm{H} 3 \mathrm{~K} 4$ are trimethylated by the Set1/COMPASS complex, while H3K4me 3 in humans are mediated by various complexes: MLL (1-4) complexes and Set1 (A/B) complexes [10, 11]. Of these, human Set1 complexes are most similar to yeast Set1/COMPASS complex and contribute significantly to global H3K4me3 in mammalian cells [12-14]. Human Set1 complex is composed of several different subunits, containing Set1, Ash2, Wdr5, Wdr82, Rbbp5, and CXXC1. According to the previous report, RNA polymerase II (RNA pol II) is closely related to $\mathrm{H} 3 \mathrm{~K} 4 \mathrm{me} 3$ and recruits Set 1 to the $5^{\prime}$ portion of active mRNA coding regions [15].

Gene expression in DNA virus is subject to epigenetic regulation through host-encoded enzymes. During viral life cycle, latent and lytic infections, histone modification is one of the keys to regulating the transcriptional activation or repression of viral genes. Previous studies have reported that lytic genes in the lytic phase are characterized by high levels of active histone marks, such as $\mathrm{H} 3 \mathrm{~K} 4 \mathrm{me} 3$ and $\mathrm{H} 3 / \mathrm{H} 4$ acetylation, whereas the viral genome in the latent phase is associated with repressive histone marks, such as $\mathrm{H} 3 \mathrm{~K} 9$ methylation and $\mathrm{H} 3$ hypoacetylation [16-19].

Kaposi's sarcoma-associated herpesvirus (KSHV), also termed human herpesvirus- 8 , is a pathogenic agent of primary effusion lymphoma, multicentric Castleman disease, and Kaposi's sarcoma [20, 21]. Similar to other herpesviruses, KSHV has two life cycles and is controlled by epigenetic histone modification $[22,23]$. The replication and transcription activator (RTA) encoded by open reading frame (ORF) 50 of KSHV mediates the switch from the latent to lytic cycle [24]. Sodium butyrate $(\mathrm{NaB})$ and 12-O-tetradecanynoyl-phorbol-13-acetate (TPA) are chemical agents known to inhibit the histone deacetylase and are used to induce the lytic replication of KSHV [25]. During latency, the RTA gene is tightly repressed by association between the RTA promoter and histone deacetylase (HDAC). Upon treatment with an HDAC inhibitor, HDAC dissociates from RTA promoter, which allows histone acetyltransferases and transcription machinery access to the promoter regions. Finally, it induces hyper- acetylation of histones and activates the viral lytic genes [26].

Previously, it is reported that $\mathrm{H} 3 \mathrm{~K} 4 \mathrm{me} 3$ by Set1 is involved in lytic infection of human herpes simplex virus-1 [17]. In KSHV, epigenetic histone modifications including H3K4me3, H3K27me3, H3K9me3, and H3 acetylation were analyzed genome-wide during latency and reactivation [23]. We thought that it is necessary to develop more specific and detailed approaches. In this paper, we identified global H3K4 methylation at the protein level in KSHV-infected cells during reactivation. Using chromatin immunoprecipitation (ChIP) assay, we investigated the change of $\mathrm{H} 3 \mathrm{~K} 4 \mathrm{me} 3$ levels on the several lytic-related sites of KSHV genome during reactivation. Additional experiments were conducted to determine whether the recruitment of human Setl complex and RNA pol II at the genomic loci critical for lytic infection are facilitated. Consequently, we confirmed that trimethylation on H3K4 by human Set 1 complex are quantitatively altered with lytic gene activation during reactivation of KSHV.

\section{Materials and Methods}

Cell Lines and Cell Culture

TREx BCBL-1/pcDNA5/FRT/TO (TREx BCBL-1) and TREx BCBL-1/RTA (received from Dr. Jung from Nakamura et al. [27]) are KSHV-positive cell lines. The TREx BCBL-1/RTA cell line carries a tetracycline-inducible RTA gene. These cell lines were grown in RPMI-1640 medium (WelGENE) supplemented with $10 \%$ fetal bovine serum. Cells were treated with $1 \mu \mathrm{g} / \mathrm{ml}$ doxycycline (Dox) and incubated during the indicated time.

\section{Antibodies}

Antibodies used in Western blot were obtained from rabbit serum: antihistone $\mathrm{H} 3$ antibody, antidimethyl-histone $\mathrm{H} 3$ (Lys4) antibody, antitrimethyl-histone $\mathrm{H} 3$ (Lys4) antibody, anti-vIRF1 antibody, anti-K8 antibody, and anti-K8.1 antibody. Anti- $\beta$-actin antibody was purchased from Santa Cruz (Cat. No. sc-47778). The following antibodies were used for ChIP assay: rabbit antihistone H3 antibody (Millipore, Cat. No. 06-755), rabbit antitrimethylhistone H3 (Lys4) antibody (Millipore, Cat. No. 07-473), rabbit anti-RNA polymerase II antibody (Bethyl Lab., Cat. No. A300653A), rabbit anti-hSET1 antibody (Bethyl Lab., Cat. No. A300289A), rabbit anti-ASH2 antibody (Bethyl Lab., Cat. No. A300107A), and rabbit anti-WDR5 antibody (Bethyl Lab., Cat. No. A300-429A).

\section{Western Blot}

Cells were washed with ice-cold PBS and were lysed with highsalt EBC buffer (50 mM Tris-HCl; pH 7.5, $600 \mathrm{mM} \mathrm{NaCl}, 0.5 \%$ Nonidet P-40, $50 \mathrm{mM} \mathrm{NaF}, 200 \mu \mathrm{M}$ sodium orthovanadate, $1 \mathrm{mM}$ phenylmethylsulfonyl fluoride). Cell lysates were mixed with $5 \times$ SDS sample buffer and heated at $100^{\circ}$ for $5 \mathrm{~min}$. The protein concentration was determined using Bradford assay (Bio-Rad) and samples were loaded onto the SDS-polyacrylamide gel (6- 
15\%). After separation and transfer, PVDF membranes were blocked with 5\% skim milk in TBST [TBS; $20 \mathrm{mM}$ Tris-HCl; pH $7.5,120 \mathrm{mM} \mathrm{NaCl}+0.1 \%(\mathrm{v} / \mathrm{v})$ Tween 20] for $1 \mathrm{~h}$ and incubated with a specific antibody $(1: 1,000)$ for $1 \mathrm{~h}$ at room temperature. And then, membranes were washed five times (5 min each) with TBST and incubated for $1 \mathrm{~h}$ at room temperature with anti-rabbit IgG-HRP-linked secondary antibody (GE Healthcare, Cat. No. NA934) diluted 1:10,000. After washing five times with TBST, the membranes were developed by using Super Signal West Pico Chemiluminescent Substrate (Thermo Scientific, Cat. No. 34080).

ChIP Assay

Untreated cells or treated cells with doxycycline $\left(2 \times 10^{7}\right.$ cells $)$ were crosslinked with $1 \%$ formaldehyde for $10 \mathrm{~min}$ at $37^{\circ}$. The reaction was stopped by addition of glycine (final $0.125 \mathrm{M}$ ) and cells were washed with ice-cold PBS containing protease inhibitor (PI; $1 \mathrm{~mm}$ phenylmethylsulfonyl fluoride, $1 \mu \mathrm{g} / \mathrm{ml}$ leupeptin). The cell pellet was lysed in SDS lysis buffer (1\% SDS, $10 \mathrm{~mm}$ EDTA, $50 \mathrm{~mm}$ Tris; $\mathrm{pH} 8.1, \mathrm{PI}$ ) for $10 \mathrm{~min}$ at $4^{\circ}$, and sonicated using Bio-Ruptor sonicator (Cosmo Bio Co. Ltd.; 7 cycles, pulse on $2 \mathrm{~s} \times$ off $13 \mathrm{~s}$ ) to shear the DNA to lengths of about $500 \mathrm{bp}$. Lysates were centrifuged at $12,000 \mathrm{rpm}$ for $20 \mathrm{~min}$ at $4^{\circ}$ and the supernatant was diluted with IP buffer (0.01\% SDS, 1.1\% Triton X-100, 1.2 mM EDTA, $16.7 \mathrm{~mm}$ Tris-HCl; pH 8.1, $167 \mathrm{~mm} \mathrm{NaCl}, \mathrm{PI})$, and $2 \%$ of the diluted sample was saved for use as input control. The remainder of supernatant was incubated with specific antibody (1-2 $\mu \mathrm{g})$ overnight at $4^{\circ}$ with rotation and followed by addition of protein Aand $\mathrm{G}$-agarose beads for $1 \mathrm{~h}$ at $4^{\circ}$ with rotation. The immune complex was collected by briefly centrifuging and washing sequentially for $5 \mathrm{~min}$ each in low-salt immune complex wash buffer $(0.1 \%$ SDS, 1\% Triton X-100, 2 mM EDTA, 20 mM Tris-HCl; $\mathrm{pH} 8.1,150 \mathrm{~mm} \mathrm{NaCl}$ ), high-salt immune complex wash buffer (0.1\% SDS, 1\% Triton X-100, 2 mM EDTA, 20 mM Tris-HCl; pH $8.1,500 \mathrm{mM} \mathrm{NaCl}), \mathrm{LiCl}$ immune complex wash buffer $[0.25 \mathrm{M}$ LiCl, 1\% IGEPAL, CA630, 1\% deoxycholic acid (sodium salt), 1 mM EDTA, 10 mM Tris-HCl; pH 8.1], and washed twice with TE buffer (10 mM Tris-HCl; pH 8.0, 1 mM EDTA). The DNA-protein complexes were extracted from agarose beads by adding elution buffer ( $1 \%$ SDS, $0.1 \mathrm{M} \mathrm{NaHCO}_{3}$ ). To reverse crosslinking, elutes and input were treated with $20 \mu \mathrm{l}$ of $5 \mathrm{M} \mathrm{NaCl}$ for $4 \mathrm{~h}$ (or overnight) at $65^{\circ}$, and $2 \mu \mathrm{l}$ of $10 \mathrm{mg} / \mathrm{ml}$ proteinase $\mathrm{K}$ for $1 \mathrm{~h}$ at $45^{\circ}$. DNA fragments were purified with QIAquick PCR purification kit (QIAGEN) and analyzed by quantitative real-time PCR. ChIP assay was repeated at least two times using biologically independent samples.

\section{Quantitative Real-Time PCR}

For PCR, $2 \mu \mathrm{l}$ from a $50 \mu \mathrm{l}$ DNA extraction was used as PCR templates. Quantitative real-time (RT)-PCR was performed by Rotor Gene Q machine (Qiagen) and KAPA SYBR FAST qPCR Master Mix (KAPA Biosystem, Cat. No. KK4602). Each of the promoters was amplified by RT-PCR primers (table 1). The $\beta$ actin primer set was used as an internal control. PCR conditions were as follows: for initial denaturing $95^{\circ}$ for $3 \mathrm{~min}, 50$ cycles of $95^{\circ}$ for $3 \mathrm{~s}, 60-62^{\circ}$ for $20 \mathrm{~s}$ in the Rotor-Gene Q series software. Quantification of amplifications was based on standard curves for each of primer set. The relative enrichments for each precipitated sample were normalized to an internal control $\beta$-actin and the input DNA. The relative enrichments of precipitated sample with $\mathrm{H} 3 \mathrm{~K} 4 \mathrm{me} 3$ antibody were further normalized with $\mathrm{H} 3$ oc-

Alteration of H3K4me3 on Lytic Gene

Promoters of KSHV during Reactivation cupancy $[28,29]$. The relative enrichment values of Dox-treated cells were compared relative to the enrichment values for the untreated cells.

\section{Statistical Analysis}

Means and SD were calculated for quantitative data. The collected data for each group was compared by repeated measures analysis of variance using a statistical software package.

\section{Results}

KSHV Reactivation Does Not Change the Global Level of Histone H3 Lysine 4 Methylation in KSHV-Infected Cells

Some tumors reveal the specific pattern of global histone modifications [30]. We conducted experiments to ascertain whether the switch from the latent to lytic phase changes the overall cellular levels of H3K4 methylation in KSHV-infected cells. RTA expressed from TREx BCBL-1/RTA cells treated with Dox induces the reactivation of KSHV. Using these cell lines, we first tested for ability of Dox-induced RTA to activate the lytic genes expression. TREx BCBL-1/RTA cell lines and its control cell lines, TREx BCBL-1, were treated with Dox $(1 \mu \mathrm{g} / \mathrm{ml})$ and harvested at the indicated times and immediately lysed. Cell extracts were fractionated by SDSPAGE and followed by Western blot using specific antibodies (fig. 1). We monitored the expression of several lytic proteins at various time points after Dox treatment. Lytic K8, K8.1, and viral interferon regulatory factor 1 (vIRF1) proteins were increased, implying that upon Dox treatment, TREx BCBL-1/RTA cells were induced into the lytic cycle. $\beta$-actin and latency-associated nuclear antigen (LANA), which were consistently expressed during the latent and lytic phases, were used as controls. Our results showed no change in levels of $\mathrm{H} 3, \mathrm{H} 3 \mathrm{~K} 4 \mathrm{me} 2$, or $\mathrm{H} 3 \mathrm{~K} 4 \mathrm{me} 3$, indicating that $\mathrm{KSHV}$ reactivation does not affect the global levels of H3K4 methylation in the host cells.

\section{H3K4me3 Modification Associates with Activation of} Lytic Gene during KSHV Reactivation

Because expression of KSHV lytic genes is increased significantly in the lytic replication, alteration of histone modification at the lytic gene promoters is inevitable. To measure changes in $\mathrm{H} 3 \mathrm{~K} 4 \mathrm{me} 3$ states on the lytic-related regions of the KSHV genome under Dox treatment, we performed ChIP assays using antibodies against the $\mathrm{H} 3$ and H3K4me3. The amount of immunoprecipitated DNA was evaluated by quantitative (q) RT-PCR with specific 
Fig. 1. Western blot analysis of KSHV proteins and H3K4 methylation in Dox-treated TREx BCBL-1/pcDNA5/FRT/TO or in Dox-treated TREx BCBL-1/RTA cells. Cells were treated with $1 \mu \mathrm{g} / \mathrm{ml}$ Dox and scraped at the indicated times. Equal amounts of total proteins were analyzed by Western blotting with specific antibodies. Anti- $\beta$-actin antibody was used as control.

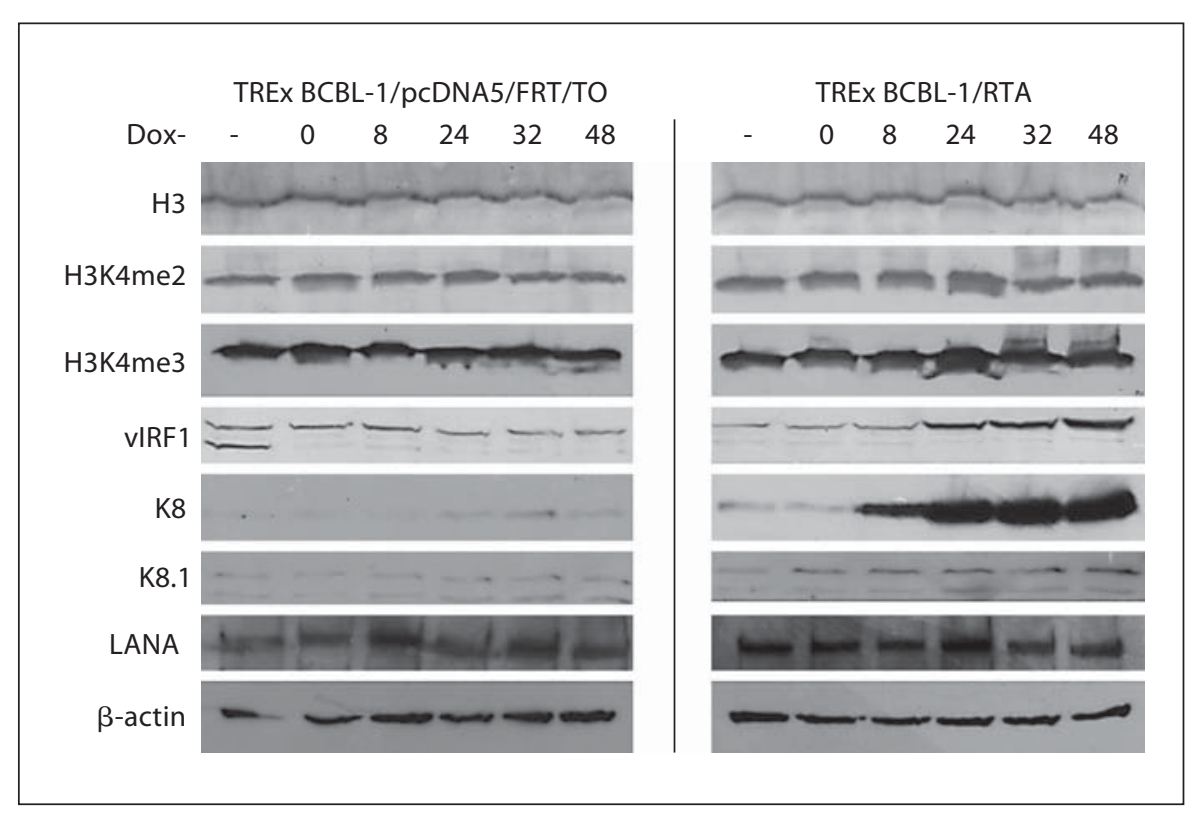

Table 1. Primers used for quantitative RT-PCR

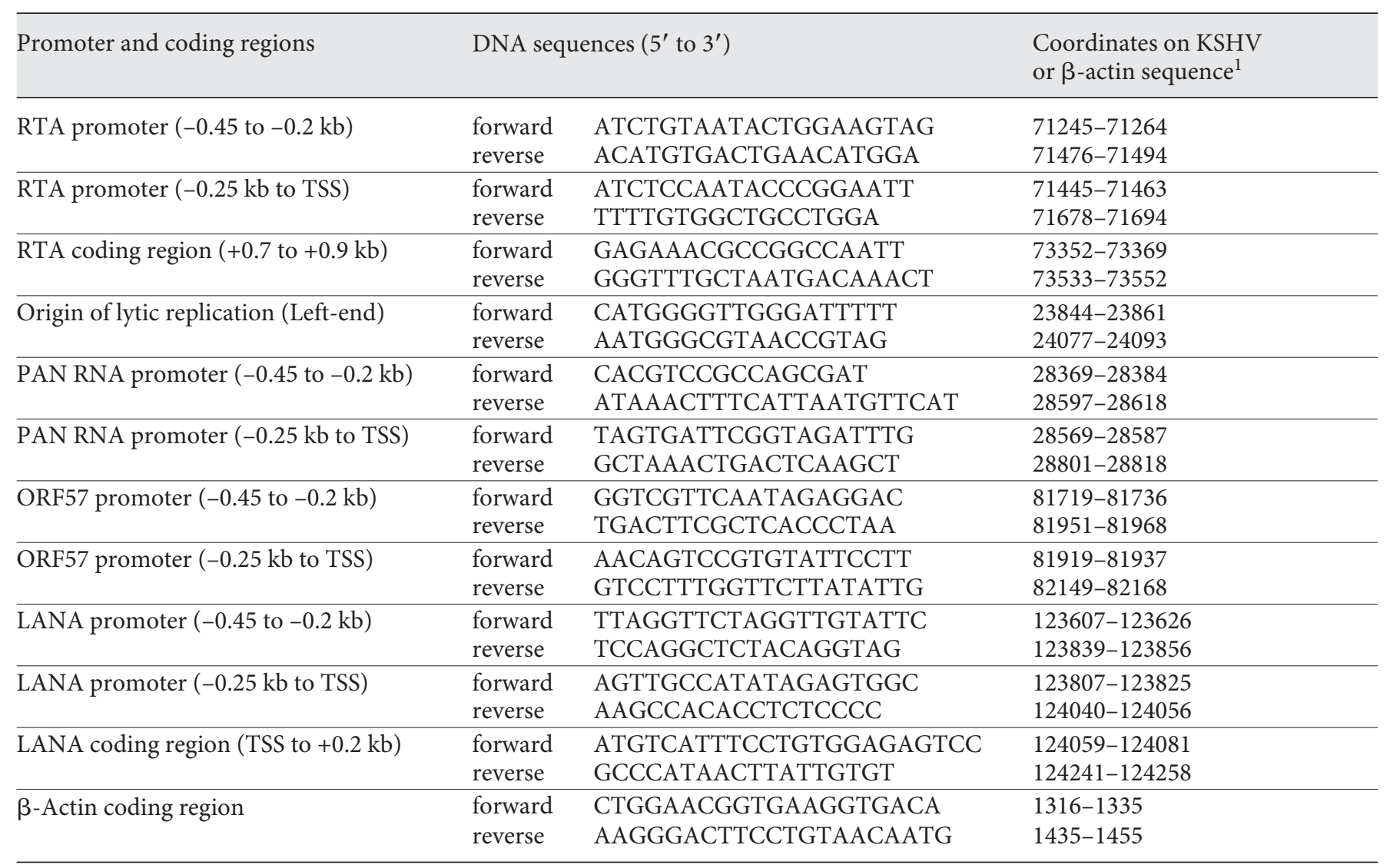

TSS $=$ Transcriptional start site.

${ }^{1}$ Primers were designed according to the sequence of KSHV (AF148805.2)/ $\beta$-actin (X00351.1) in the GenBank. 
primers. For qRT-PCR analysis, we chose several candidate genomic loci, including RTA, PAN RNA, ORF57, LANA, and left end-origin of lytic replication (OriLyt-L). These genes, such as PAN RNA and ORF57, have been identified as downstream targets of RTA, and OriLyt-L plays a crucial role in the lytic replication. We regarded $250 \mathrm{bp}$ interval sequences within -0.45 to $-0.2 \mathrm{~kb}$ and $-0.25 \mathrm{~kb}$ to the transcriptional start sites (TSS) as promoter regions on the assumption that each promoter is closely located upstream of their TSS. The oriLyt domain of OriLyt-L and coding region (+0.7 to $+0.9 \mathrm{~kb})$ of RTA, and coding region (TSS to $+0.25 \mathrm{~kb}$ ) of LANA are added for analysis (table 1). Since the histone occupancy is negatively correlated with transcriptional activation, active histone modification on the lytic gene promoters contributes to histone loss during KSHV reactivation [31]. Therefore, the enrichment of precipitated samples was normalized to internal control and input DNA and that of $\mathrm{H} 3 \mathrm{~K} 4 \mathrm{me} 3$ was further normalized to the $\mathrm{H} 3$ occupancy. The relative enrichment for each Dox treatment was calculated relative to the values of untreated cells (fig. 2). Normalization of $\mathrm{H} 3 \mathrm{~K} 4 \mathrm{me} 3$ levels with respect to $\mathrm{H} 3 \mathrm{oc}-$ cupancy revealed that the Dox treatment of TREx BCBL1/RTA cells leads to upregulation of $\mathrm{H} 3 \mathrm{~K} 4 \mathrm{me} 3$ at the putative RTA promoter. The levels of $\mathrm{H} 3 \mathrm{~K} 4 \mathrm{me} 3$ at the putative PAN RNA and ORF57 promoters, as well as RTA coding region and OriLyt-L, also increased after induction of the lytic phase by Dox treatment. The levels of $\mathrm{H} 3 \mathrm{~K} 4 \mathrm{me} 3$ at the putative promoters and coding region of LANA were somewhat raised in reactivated cells, but it seems small compared to the variation of genomic loci that are activated during the lytic phase. Taken together, these findings suggest that upon KSHV reactivation by RTA expression, H3K4me3 is associated with transcriptional activation of lytic genes.

\section{Set1 Is Involved in Activation of Lytic Gene Promoter} during the Lytic Infection through Regulating the H3K $4 \mathrm{me} 3$

In humans, H3K4me3 is controlled by human Set1 complex and Set1 is H3K4 methytransferase, a subunit of this complex. To examine whether the enrichment of $\mathrm{H} 3 \mathrm{~K} 4 \mathrm{me} 3$ is due to recruitment of Set1 to the relevant regions, we carried out ChIP assay using a specific antibody to Set1 (fig. 3). At the putative promoter of lytic genes in Dox-treated TREx BCBL-1/RTA cells, the recruitment of Set1 was clearly induced, compared with untreated cells. Set1 was also enriched on the coding region of RTA and OriLyt-L. On the other hand, we did not observe a notable difference in the recruitment of Set1 on the putative LANA promoters and coding region. We found that the recruitment of Set1 to the lytic-related regions is greatly induced in response to the expression of RTA, indicating that Set1 functions in the transcriptional activation of lytic genes through the mediating H3K4me3.

\section{Recruitment of RNA pol II Is Enriched at the Active} Lytic Genes

RNA pol II directly mediates the initiation and elongation of transcription and coordinates the recruitment of Set1. We conducted ChIP assay to define the changes of spatial distribution of RNA pol II during reactivation. Dox-treated cells and untreated cells were crosslinked and precipitated with anti-RNA pol II antibody. The enrichment of RNA pol II was quantified by qRT-PCR using pairs of primers specific to the promoters and coding regions (fig. 4). The results strongly indicate that RTA expression in KSHV-infected cells led the binding of RNA pol II to putative lytic gene promoters and coding region and OriLyt-L. The values of increase varied depending on the promoter regions, but were bigger than that of control cells. Exceptionally, there was little difference in the recruitment of RNA pol II to the $-0.25 \mathrm{~kb}$ to TSS region of RTA upstream. Meanwhile, we also found that KSHV reactivation increases the level of RNA pol II at the one of putative LANA promoters $(-0.25 \mathrm{~kb}$ to TSS) and LANA coding region (TSS to $+0.2 \mathrm{~kb}$ ), as previously demonstrated [23]. Based on our results, we propose that RNA pol II is associated with lytic gene promoters and induces the H3K4me3 by recruiting the Set1. Moreover, the increase of interaction between RNA pol II and DNA contributes to the transactivation of lytic gene during reactivation of KSHV.

\section{Ash2 Is Highly Recruited to Lytic Gene Promoter}

during the Switch from Latent to Lytic Infection

Cps40 and Cps60 components of yeast Set1/COMPASS cause a conformational change of Set1, so that its histone methyltransferase active site becomes more open, making dimethylated $\mathrm{H} 3 \mathrm{~K} 4$ easier to accomplish trimethylation [32,33]. Ash2 in human cells is conserved in a subunit of human Set1 complex with both Cps40 and Cps60, and is required for proper H3K4me3. Ash2 interacts not only with the human Set1 complex, but also with other histone methyltransferase-containing complexes, including MLL (1-4) complexes [34]. We performed ChIP assay to investigate whether the occupancy of Ash2 at the lytic gene promoter is enhanced by the switch from latency to lytic cycle of KSHV (fig. 5). We observed that in 


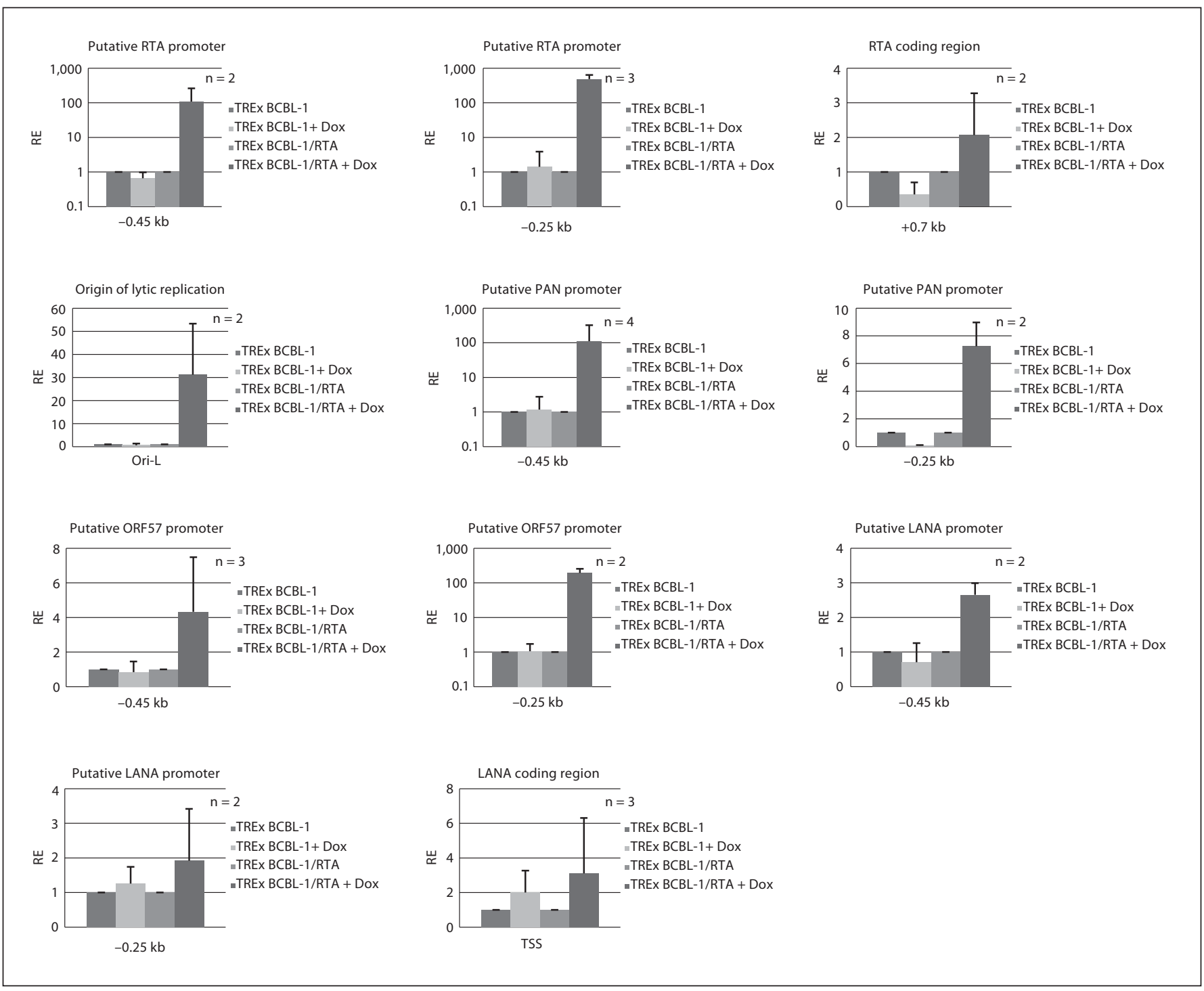

Fig. 2. ChIP analysis of $\mathrm{H} 3 \mathrm{~K} 4 \mathrm{me} 3$ associated with viral lytic gene promoter regions during KSHV reactivation. Cells were treated with Dox $(1 \mu \mathrm{g} / \mathrm{ml})$ or without Dox, followed by crosslinking with $1 \%$ formaldehyde. Immunoprecipitation was performed with anti-H3K4me3 antibody. The relative H3K4me3 levels were measured by qRT-PCR and normalized with an internal control ( $\beta$ -

response to Dox treatment, Ash2 was highly enriched on the RTA promoter region in TREx BCBL-1/RTA cells. Ash2 was recruited to the OriLyt-L and putative PAN RNA and ORF57 promoters, but not to the putative LANA promoters and coding regions (TSS to $+0.2 \mathrm{~kb}$ ), indicating that RTA expression in the KSHV-infected cells enhances the recruitment of Ash2 to the active gene promoters during lytic phase. actin) and input DNA. Respective relative enrichment (RE) values of H3K4me 3 of Dox-treated cells were further normalized against the RE values of $\mathrm{H} 3 \mathrm{~K} 4 \mathrm{me} 3$ and compared with untreated cells. Error bars represent the SD and ' $n$ ' is the number of repeats; -0.45 $\mathrm{kb}(-0.45$ to $-0.2 \mathrm{~kb}),-0.25 \mathrm{~kb}(-0.25 \mathrm{~kb}$ to TSS), TSS (TSS to $+0.2 \mathrm{~kb}),+0.7(+0.7$ to $+0.9 \mathrm{~kb})$.

\section{KSHV Reactivation Causes the Enrichment of Wdr5}

Recruitment at the Promoter of Lytic Genes

Wdr5 is a core component of the Set1-family complex and is critical for assembly and integrity. It binds with the $\mathrm{H} 3$ tail independently from the methylation state of $\mathrm{H} 3 \mathrm{~K} 4$ and is engaged in (mono-, di-, tri-)methylation of H3K4. However, it was proposed that WDR5 remains associated with H3K4me2 for a longer time, which 


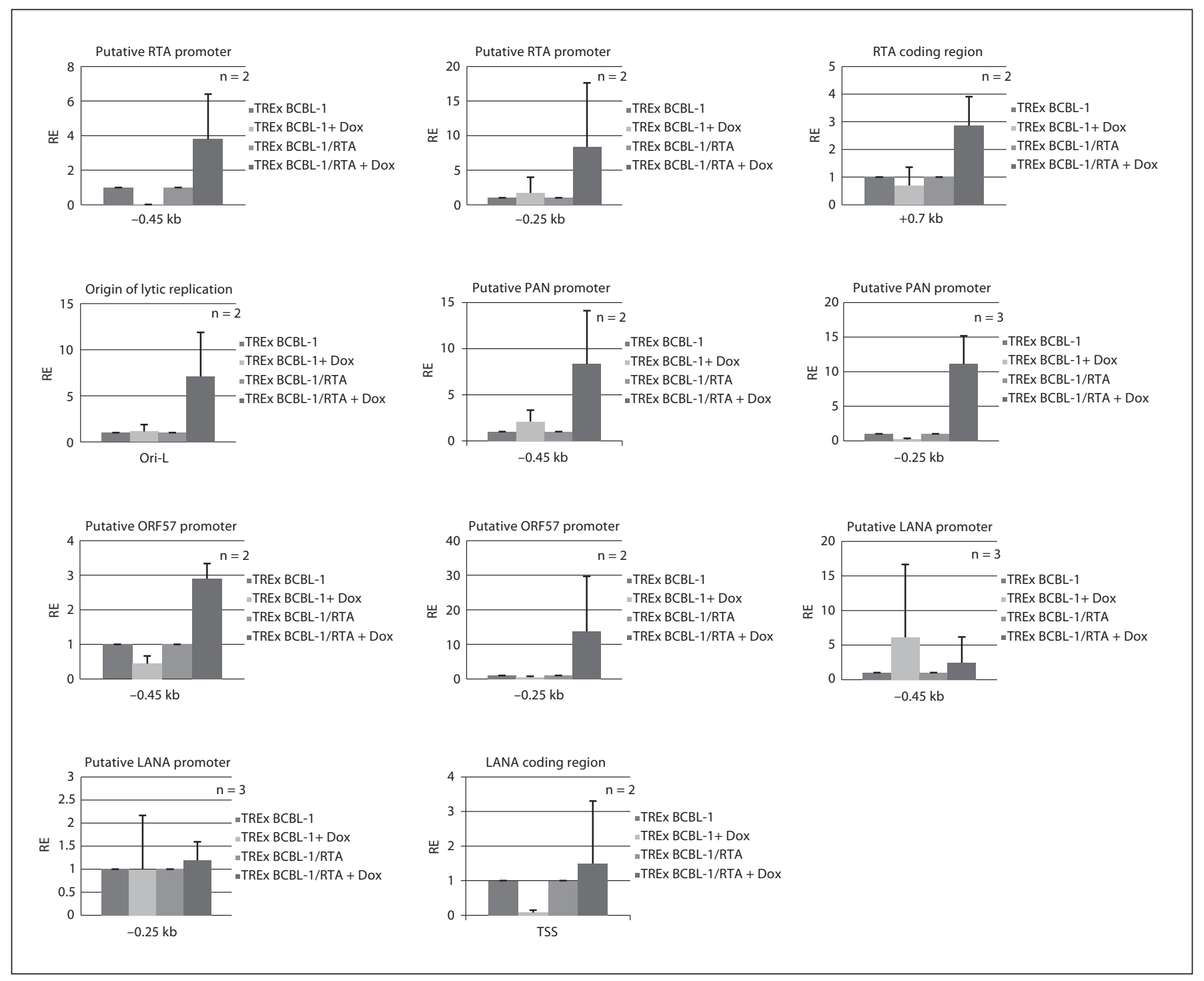

Fig. 3. ChIP analysis of Set1 associated with viral lytic gene promoter regions during KSHV reactivation. Cells were treated with Dox $(1 \mu \mathrm{g} / \mathrm{ml})$ or without Dox, followed by crosslinking with $1 \%$ formaldehyde. Immunoprecipitation was performed with antiSet1 antibody. The recruitment of Set1 to regions of interest was measured by qRT-PCR and normalized with an internal control
( $\beta$-actin) and input DNA. Respective RE values of H3K4me3 of Dox-treated cells were compared with untreated cells. Error bars represent the SD and ' $\mathrm{n}$ ' is the number of repeats; $-0.45 \mathrm{~kb}(-0.45$ to $-0.2 \mathrm{~kb}),-0.25 \mathrm{~kb}(-0.25 \mathrm{~kb}$ to TSS), TSS (TSS to $+0.2 \mathrm{~kb}),+0.7$ $(+0.7$ to $+0.9 \mathrm{~kb})$. serves for further methylation [35-37]. To identify whether Wdr5 is involved in $\mathrm{H} 3 \mathrm{~K} 4 \mathrm{me} 3$ at the promoter regions of lytic genes and OriLyt-L, Chip assays using Wdr5 antibody were performed following Dox treatments (fig. 6). We found that Dox treatment of TREx BCBL-1/RTA cells induced the enrichment of Wdr5 binding at the putative RTA promoter and coding region $(+0.7$ to $+0.9 \mathrm{~kb})$. Our data revealed that Wdr5 is also recruited to the two putative PAN RNA promoters and one putative ORF57 ( -0.45 to $-0.2 \mathrm{~kb})$ promoter and OriLyt-L, reflecting that the enrichment of Wdr5 binding is closely related with transcriptional activation of lytic genes during KSHV reactivation. However, Dox treatment does not change the recruitment level of Wdr5 to the putative ORF57 promoter ( $-0.25 \mathrm{~kb}$ to TSS) in TREx BCBL-1/RTA cells. Although the recruitment of 


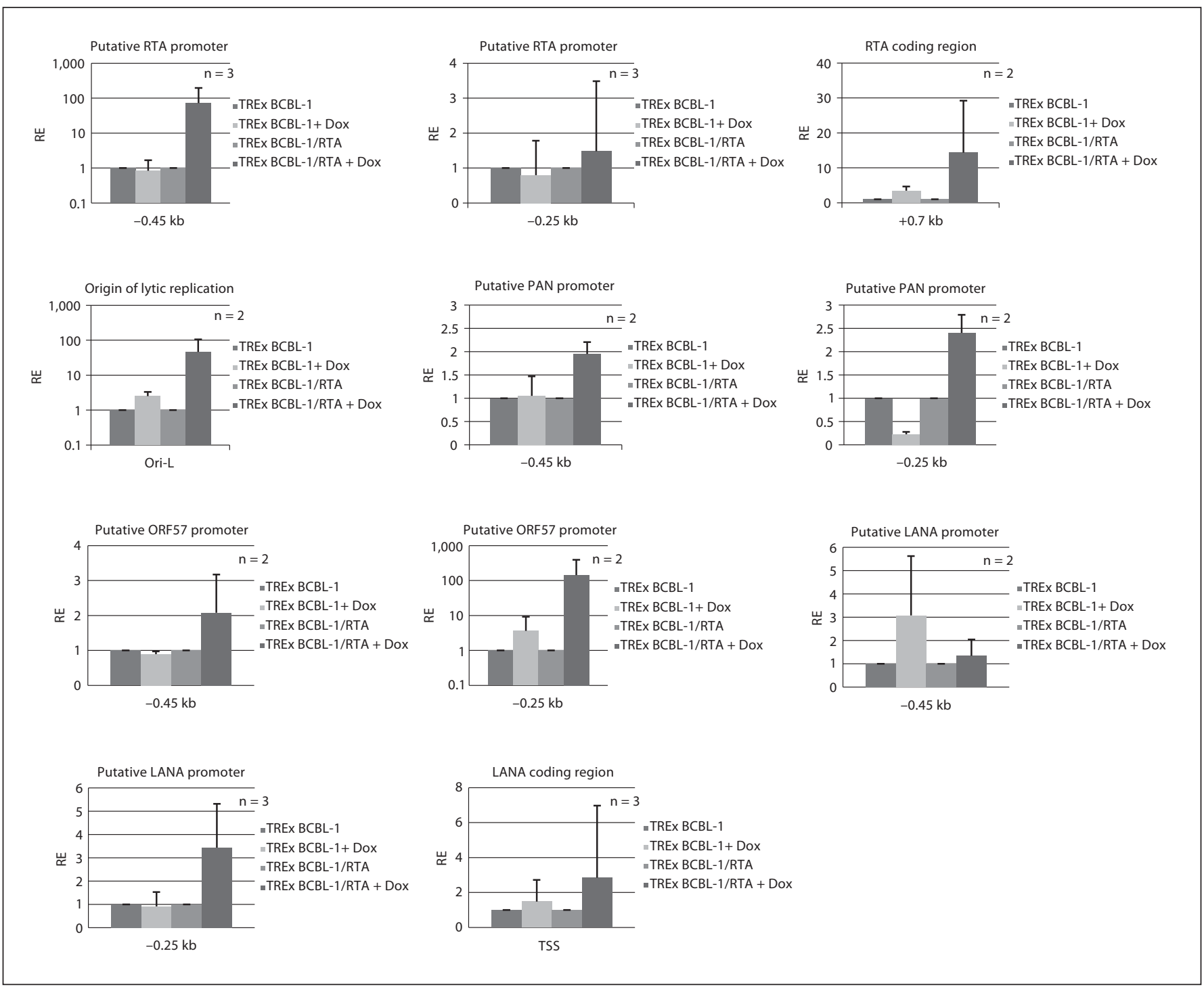

Fig. 4. ChIP analysis of RNA pol II associated with viral lytic gene promoter regions during KSHV reactivation. Cells were stimulated with Dox $(1 \mu \mathrm{g} / \mathrm{ml})$ for $12 \mathrm{~h}$ or mock-treated and followed by crosslinking with $1 \%$ formaldehyde. Chromatin fragments were immunoprecipitated with specific antibody against RNA pol II. The recruitment of RNA pol II to regions of interest was mea-

Wdr5 was slightly increased at the regions related with LANA, these unexpected results require further investigation. These findings suggest that $\mathrm{Wdr} 5$ participates in activation of lytic gene transcription during the lytic phase along with other subunits of human Set1 complex. sured by qRT-PCR and normalized with an internal control ( $\beta$ actin) and input DNA. Respective RE values of RNA pol II of Doxtreated cells were compared with untreated cells. Error bars represent the SD and ' $\mathrm{n}$ ' is the number of repeats; $-0.45 \mathrm{~kb}(-0.45$ to $-0.2 \mathrm{~kb}),-0.25 \mathrm{~kb}(-0.25 \mathrm{~kb}$ to TSS), TSS (TSS to $+0.2 \mathrm{~kb}),+0.7$ $(+0.7$ to $+0.9 \mathrm{~kb})$.

\section{Discussion}

$\mathrm{KSHV}$ is classified into the $\gamma$-herpesvirus subfamily with Epstein-Barr virus [38]. KSHV operates via both latent and lytic phases. During the latent phase, the virus exists as a extrachromosomal circular episome which is tethered to the host chromosome, and expresses only limited genes, including LANA and vIRF3 [39-41]. In 


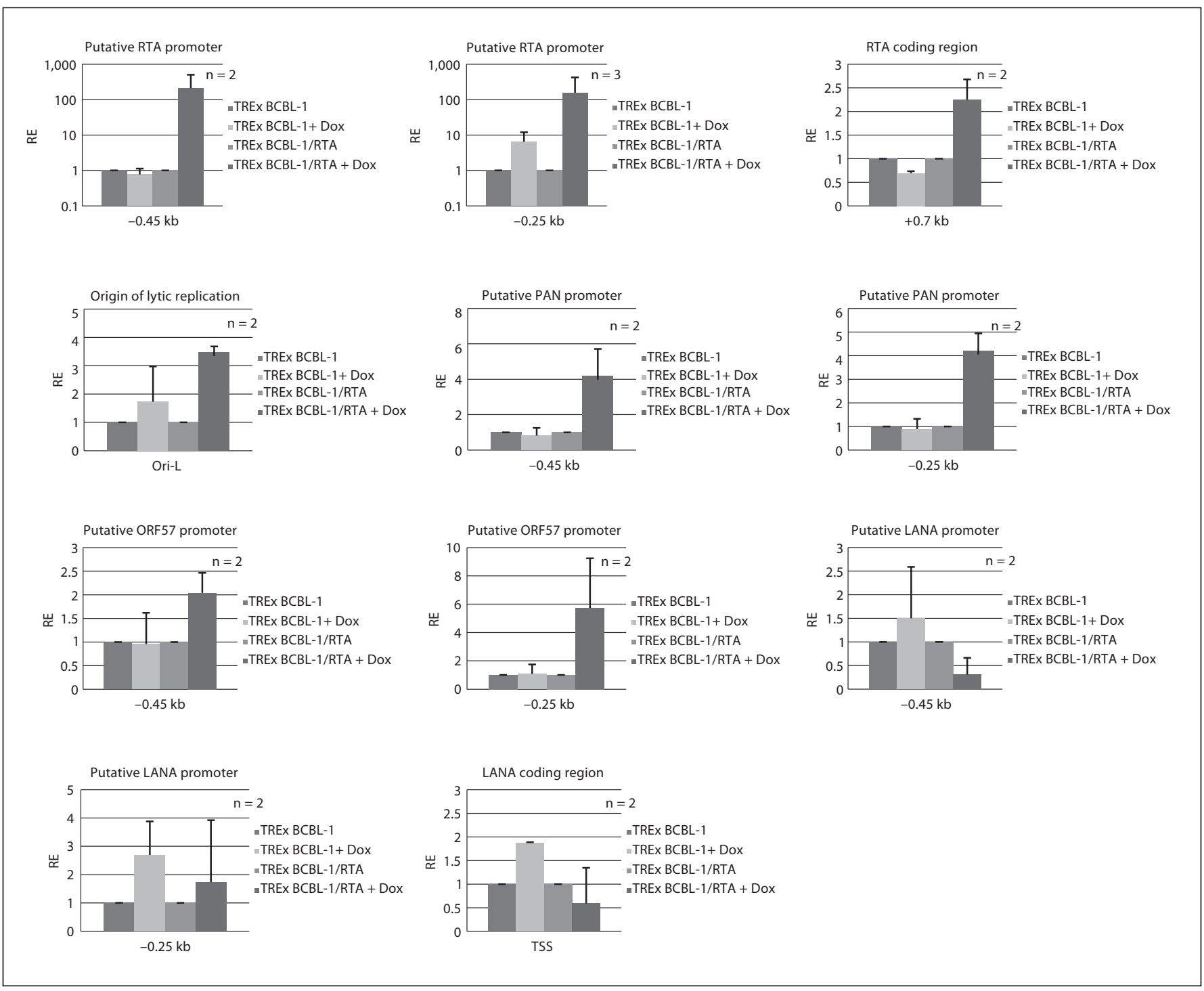

Fig. 5. ChIP analysis of Ash2 associated with viral lytic gene promoter regions during KSHV reactivation. Cells were treated with Dox $(1 \mu \mathrm{g} / \mathrm{ml})$ or without Dox, followed by crosslinking. Immunoprecipitation was performed with anti-Ash2 antibody. The recruitment of Ash 2 to regions of interest was measured by qRT-
PCR and normalized with an internal control ( $\beta$-actin) and input DNA. Respective RE values of Ash2 of Dox-treated cells were compared with untreated cells. Error bars represent the SD and ' $\mathrm{n}$ ' is the number of repeats; $-0.45 \mathrm{~kb}(-0.45$ to $-0.2 \mathrm{~kb}),-0.25 \mathrm{~kb}$ $(-0.25 \mathrm{~kb}$ to TSS), TSS (TSS to $+0.2 \mathrm{~kb}),+0.7(+0.7$ to $+0.9 \mathrm{~kb})$. contrast, during the lytic phase, viral genes required for production of virion progeny and destruction of host cells are expressed. KSHV RTA is necessary and sufficient to reactivate from latent to lytic cycle in infected cells $[24,42]$. KSHV reactivation can be made by chemical agents, such as TPA and NaB, which act as HDAC inhibitors [25], suggesting that during latent and ly tic cycles of KSHV, gene expression is controlled by epigenetic histone modification.
Previous studies have identified that posttranslational modification of histone determines the structure and condensation of chromatin, which affects the transcriptional activity. H3K4 methylation is a representative histone posttranslational modification, which is linked to the transcription activation. Certain histone modification patterns can be used as indicators of cell physiology change [9]. For instance, phosphorylation of histone $\mathrm{H} 3$ serine 10 is connected with chromosome condensation 


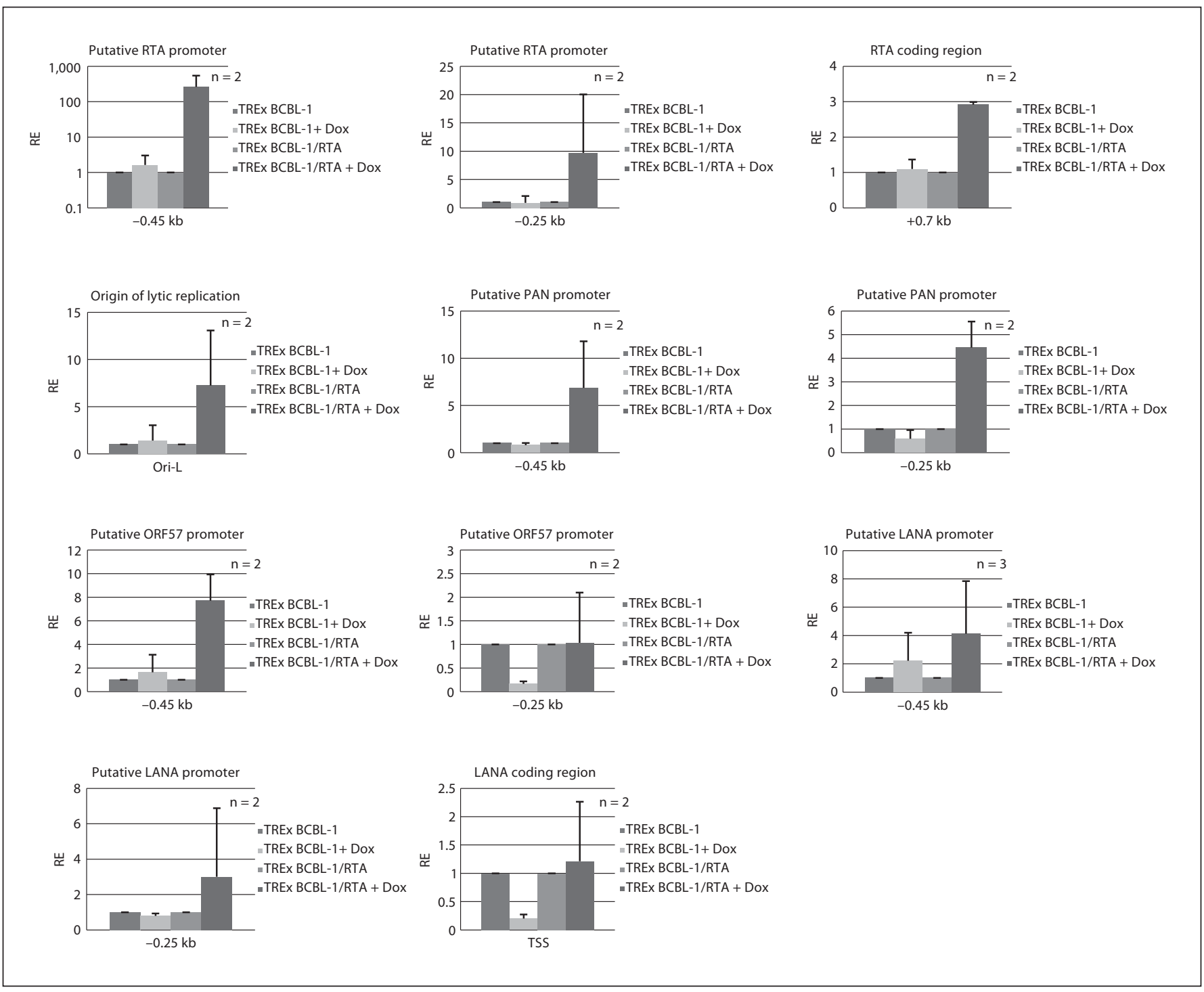

Fig. 6. ChIP analysis of Wdr5 associated with viral lytic gene promoter regions during KSHV reactivation. ChIP assays were performed with cells treated with Dox $(1 \mu \mathrm{g} / \mathrm{ml})$ or without Dox. Cells were crosslinked with $1 \%$ formaldehyde and immunoprecipitated with anti-Wdr5 antibody. The recruitment of Wdr5 to regions of interest was measured by qRT-PCR and normalized with an internal control ( $\beta$-actin) and input DNA. Respective RE values of Wdr5 of Dox-treated cells were compared with untreated cells. Error bars represent the SD and ' $n$ ' is the number of repeats; $-0.45 \mathrm{~kb}(-0.45$ to $-0.2 \mathrm{~kb}),-0.25 \mathrm{~kb}(-0.25 \mathrm{~kb}$ to TSS), TSS (TSS to $+0.2 \mathrm{~kb}),+0.7(+0.7$ to $+0.9 \mathrm{~kb})$. and highly detected in mitotic cells $[43,44]$. Most viruses, including KSHV, manipulate to optimize host cell environment for viral replication and pathogenesis. We conducted Western blot to ascertain whether KSHV reactivation transforms the levels of $\mathrm{H} 3 \mathrm{~K} 4$ methylation in the total chromatin of KSHV-infected cells (fig. 1). We did not observe the effect of reactivation on the change of overall levels of H3K4 methylation. Recently, a study on the epigenetic modification of KSHV showed the change of $\mathrm{H} 3 \mathrm{~K} 4 \mathrm{me} 3$ on the lantent and lytic genomes by genome-wide analysis [23]. Based on the previous study, we thought that site-specific approaches are required to confirm this finding. In this study, when KSHV infection is converted from latency to lytic cycle, we investigated the alteration of $\mathrm{H} 3 \mathrm{~K} 4 \mathrm{me} 3$ levels at the promoter region of several lytic genes. We chose the several ge- 
nomic loci as candidates for observation. One of them is RTA, a transcriptional activator. During latency, chromatin condensation is maintained at the RTA promoter because histone acetylation at this region is relatively low. For this reason, the chromatin structure of the RTA promoter plays an important role in determining the transactivating ability of RTA [45]. Another one is OriLyt-L. KSHV contains the two origins of lytic replication (left end and right end-origin of lytic replication). OriLyt- $\mathrm{L}$ is composed of multiple transcription factor binding sites and is sufficient to direct amplication of viral genome [46]. A third one is PAN RNA, which is the most abundant early lytic transcript of KSHV and is one of the downstream targets of RTA [47, 48]. A fourth one is ORF57, which is transactivated by RTA since it contains the RTA response element. MTA encoded by ORF57 regulates the expression of viral lytic genes with RTA and is necessary for viral lytic replication $[49,50]$. As a negative control, LANA encoded by ORF73 plays central roles in maintaining viral latency $[51,52]$. Figure 2 shows that $\mathrm{KSHV}$ reactivation led to increasing $\mathrm{H} 3 \mathrm{~K} 4 \mathrm{me} 3$ in the genomic loci critical for lytic infection. In particular, the putative RTA promoter and PAN ( -0.45 to $-0.2 \mathrm{~kb})$, ORF57 ( $-0.25 \mathrm{~kb}$ to TSS) promoter had higher enlargement levels of H3K4me3. Toth et al. [23] reported that $\mathrm{H} 3 \mathrm{~K} 4 \mathrm{me} 3$ are slightly decreased at the LANA promoter after KSHV reactivation. In our H3K4me3-ChIP data, contrary to this, we found that the levels of $\mathrm{H} 3 \mathrm{~K} 4 \mathrm{me} 3$ at the promoter and coding regions of LANA were somewhat increased relative to that of control cell lines (fig. 2). In the same study, it is reported that lack of repressive histone modification marks, $\mathrm{H} 3 \mathrm{~K} 9 \mathrm{me} 3$ and $\mathrm{H} 3 \mathrm{~K} 27 \mathrm{me} 3$, was observed during the latency while these modifications were enriched after reactivation, and that the enrichment of $\mathrm{H} 3$ acetylation remained continuous on the same regions upon reactivation. Synthetically, these findings raise the possibility that repressive histone modifications are more important to regulate the LANA expression than active histone modification. However, supplementary evidence is needed to support the possibility.

Histone $\mathrm{H} 3 \mathrm{~K} 4$ methylase Set1 is recruited to the active mRNA coding region by RNA pol II transcriptional machinery [15]. Our ChIP assay against Set1 and RNA pol II revealed that the recruitment of Set1 and RNA pol II to the putative promoter regions of RTA, PAN RNA, ORF57, and coding region of RTA was increased in Doxtreated TREx BCBL-1/RTA cells (fig. 3, 4), implying that the enrichment of $\mathrm{H} 3 \mathrm{~K} 4 \mathrm{me} 3$ on the active lytic genes during the lytic phase is correlated with Set1 and RNA

Alteration of H3K4me3 on Lytic Gene Promoters of KSHV during Reactivation pol II. In addition, the increase of interaction between RNA pol II and DNA is linked with the transactivation of the lytic gene during the lytic infection. Importantly, the increment of RNA pol II recruitment at lytic relative regions in response to reactivation does not mean that RNA pol II is almost nonexistent at lytic promoters during latency. The cooperation of RNA pol II and positive or negative transcription elongation factors is an important part of the transcription elongation control process [53-55]. The RNA pol II binding with negative transcription elongation factors becomes a paused state and aborts the productive transcription elongation even though it remains at the promoter $[53,56,57]$. A recent study showed that the negative elongation factor complex inhibits the transcription elongation at the several lytic promoters of KSHV during latency, through the interaction with RNA pol II, and that external stimuli reactivate the expression of these genes in absence of RTA [58]. Collectively, these observations indicate that viral gene expression is not completely dependent upon histone modifications and is regulated by varied and sophisticated mechanisms.

As integral members of the human Set1 complex, both Ash 2 and Wdr5 are responsible for the catalysis of $\mathrm{H} 3 \mathrm{~K}$ 4me3. In RNA interference against Ash2, reduction of Ash2 leads to loss of H3K4me3 but not mono-, dimethylation of $\mathrm{H} 3 \mathrm{~K} 4$. Wdr5 is essential for keeping the stability of Ash2 within the complex [34]. Using ChIP assay with specific antibodies to Ash2 and Wdr5, we verified that KSHV reactivation caused the enrichment of Ash2 and Wdr5 recruitment at the promoter of most lytic genes tested (fig. 5,6). The changes of recruitment to the LANA promoter differed among individual subunits. In the TREx BCBL-1 cells used as control, we also detected the weak increase or decrease of association of lytic DNA with H3K4me3, components of human Set1 complex. Such results can be explained by spontaneous reactivation of KSHV. Meanwhile, there was little difference in the binding between putative RTA promoter $(-0.25 \mathrm{~kb}$ to TSS) and RNA pol II, and in the binding between putative ORF57 promoter ( $-0.25 \mathrm{~kb}$ to TSS) and Wdr5 during KSHV reactivation. However, in the two parts, the interaction with other factors was distinctly improved. These outcomes may be due to experimental error and wrong selection of candidates; other upstream regions are necessary for association.

In this study, we demonstrated by ChIP assays that H3K4me3, a cytogenetic marker of active gene expression, is clearly involved in the transcriptional activation of lytic genes during the lytic phase and it is regulated by 
the human Set1 complex and RNA pol II. We are going to determine whether knockdown of H3K4me3 or Set1 using RNA interference or chemical inhibitor influences the transition from the latent to lytic infection. Further research is essential to establish how the human Set1 complex and RNA pol II are recruited to active lytic genes during KSHV reactivation.

\section{Acknowledgements}

We especially thank Dr. Jae U. Jung for providing TREx BCBL1/RTA. This research was supported by the Basic Science Research Program through the National Research Foundation of Korea (NRF) funded by the Ministry of Education, Science and Technology (2012R1A1A2004254), and by the Bio-industry Technology Development Program, Ministry for Food, Agriculture, Forestry and Fisheries, Republic of Korea.

\section{References}

$\checkmark 1$ Luger K, Mader AW, Richmond RK, Sargent DF, Richmond TJ: Crystal structure of the nucleosome core particle at 2.8 A resolution. Nature 1997;389:251-260.

2 Strahl BD, Allis CD: The language of covalent histone modifications. Nature 2000;403: 41-45.

13 Turner BM: Histone acetylation and an epigenetic code. Bioessays 2000;22:836-845.

$\checkmark 4$ Jenuwein T, Allis CD: Translating the histone code. Science 2001;293:1074-1080.

$\checkmark 5$ Fischle W, Wang Y, Allis CD: Histone and chromatin cross-talk. Curr Opin Cell Biol 2003; 15:172-183.

6 Fukuda H, Sano N, Muto S, Horikoshi M: Simple histone acetylation plays a complex role in the regulation of gene expression. Brief Funct Genomic Proteomic 2006;5:190-208.

7 Zhang K, Tang H, Huang L, Blankenship JW, Jones PR, Xiang F, Yau PM, Burlingame AL: Identification of acetylation and methylation sites of histone $\mathrm{H} 3$ from chicken erythrocytes by high-accuracy matrix-assisted laser desorption ionization-time-of-flight, matrix-assisted laser desorption ionizationpostsource decay, and nanoelectrospray ionization tandem mass spectrometry. Anal Biochem 2002;306:259-269.

8 Santos-Rosa H, Schneider R, Bannister AJ, Sherriff J, Bernstein BE, Emre NC, Schreiber SL, Mellor J, Kouzarides T: Active genes are tri-methylated at K4 of histone H3. Nature 2002;419:407-411.

9 Barski A, Cuddapah S, Cui K, Roh TY, Schones DE, Wang Z, Wei G, Chepelev I, Zhao K: High-resolution profiling of histone methylations in the human genome. Cell 2007;129:823-837.

-10 Yokoyama A, Wang Z, Wysocka J, Sanyal M, Aufiero DJ, Kitabayashi I, Herr W, Cleary ML: Leukemia proto-oncoprotein MLL forms a SET1-like histone methyltransferase complex with menin to regulate hox gene expression. Mol Cell Biol 2004;24:5639-5649.

-11 Cho YW, Hong T, Hong S, Guo H, Yu H, Kim D, Guszczynski T, Dressler GR, Copeland TD, Kalkum M, Ge K: PTIP associates with MLL3- and MLL4-containing histone $\mathrm{H} 3$ lysine 4 methyltransferase complex. J Biol Chem 2007;282:20395-20406.
12 Wu M, Wang PF, Lee JS, Martin-Brown S, Florens L, Washburn M, Shilatifard A: Molecular regulation of $\mathrm{H} 3 \mathrm{~K} 4$ trimethylation by Wdr82, a component of human Set1/COMPASS. Mol Cell Biol 2008;28:7337-7344.

13 Lee JH, Skalnik DG: CpG-binding protein (CXXC finger protein 1) is a component of the mammalian Set1 histone H3-Lys4 methyltransferase complex, the analogue of the yeast Set1/COMPASS complex. J Biol Chem 2005;280:41725-41731.

14 Lee JH, Tate CM, You JS, Skalnik DG: Identification and characterization of the human Set1B histone H3-Lys4 methyltransferase complex. J Biol Chem 2007;282:1341913428.

$15 \mathrm{Ng} \mathrm{HH}$, Robert F, Young RA, Struhl K: Targeted recruitment of Set1 histone methylase by elongating Pol II provides a localized mark and memory of recent transcriptional activity. Mol Cell 2003;11:709-719.

16 Kent JR, Zeng PY, Atanasiu D, Gardner J, Fraser NW, Berger SL: During lytic infection herpes simplex virus type 1 is associated with histones bearing modifications that correlate with active transcription. J Virol 2004;78:10178-10186.

17 Huang J, Kent JR, Placek B, Whelan KA, Hollow CM, Zeng PY, Fraser NW, Berger SL: Trimethylation of histone $\mathrm{H} 3$ lysine 4 by Set 1 in the lytic infection of human herpes simplex virus 1. J Virol 2006;80:5740-5746.

18 Chang LK, Liu ST: Activation of the BRLF1 promoter and lytic cycle of Epstein-Barr virus by histone acetylation. Nucleic Acids Res 2000;28:3918-3925.

19 Imai K, Togami H, Okamoto T: Involvement of histone $\mathrm{H} 3$ lysine 9 (H3K9) methyltransferase G9a in the maintenance of HIV-1 latency and its reactivation by BIX01294. J Biol Chem 2010;285:16538-16545.

20 Cesarman E, Chang Y, Moore PS, Said JW, Knowles DM: Kaposi's sarcoma-associated herpesvirus-like DNA sequences in aids-related body-cavity-based lymphomas. N Engl J Med 1995;332:1186-1191.
21 Soulier J, Grollet L, Oksenhendler E, Cacoub P, Cazals-Hatem D, Babinet P, d'Agay MF, Clauvel JP, Raphael M, Degos L, et al: Kaposi's sarcoma-associated herpesvirus-like DNA sequences in multicentric castleman's disease. Blood 1995;86:1276-1280.

22 Gunther T, Grundhoff A: The epigenetic landscape of latent Kaposi sarcoma-associated herpesvirus genomes. PLoS Pathog 2010; 6:e1000935.

23 Toth Z, Maglinte DT, Lee SH, Lee HR, Wong LY, Brulois KF, Lee S, Buckley JD, Laird PW, Marquez VE, Jung JU: Epigenetic analysis of KSHV latent and lytic genomes. PLoS Pathog 2010;6:e1001013.

24 Lukac DM, Renne R, Kirshner JR, Ganem D: Reactivation of Kaposi's sarcoma-associated herpesvirus infection from latency by expression of the ORF 50 transactivator, a homolog of the EBV R protein. Virology 1998; 252:304-312.

25 Yu Y, Black JB, Goldsmith CS, Browning PJ, Bhalla K, Offermann MK: Induction of human herpesvirus-8 DNA replication and transcription by butyrate and TPA in BCBL1 cells. J Gen Virol 1999;80:83-90.

26 Lu F, Zhou J, Wiedmer A, Madden K, Yuan Y, Lieberman PM: Chromatin remodeling of the Kaposi's sarcoma-associated herpesvirus ORF50 promoter correlates with reactivation from latency. J Virol 2003;77:1142511435.

27 Nakamura H, Lu M, Gwack Y, Souvlis J, Zeichner SL, Jung JU: Global changes in Kaposi's sarcoma-associated virus gene expression patterns following expression of a tetracycline-inducible RTA transactivator. J Virol 2003;77:4205-4220.

28 Kim JM, To TK, Ishida J, Morosawa T, Kawashima M, Matsui A, Toyoda T, Kimura H, Shinozaki K, Seki M: Alterations of lysine modifications on the histone $\mathrm{H} 3 \mathrm{~N}$-tail under drought stress conditions in Arabidopsis thaliana. Plant Cell Physiol 2008;49:15801588.

29 Ng DW, Chandrasekharan MB, Hall TC: Ordered histone modifications are associated with transcriptional poising and activation of the phaseolin promoter. Plant Cell 2006; 18:119-132. 
30 Matsuda I, Imai Y, Hirota S: Global histone modification profiles are well conserved between normal B lymphocytes and neoplastic counterparts. Pathol Oncol Res 2010;16: 447-451.

- 31 Lee CK, Shibata Y, Rao B, Strahl BD, Lieb JD: Evidence for nucleosome depletion at active regulatory regions genome-wide. Nat Genet 2004;36:900-905.

- 32 Takahashi YH, Lee JS, Swanson SK, Saraf A, Florens L, Washburn MP, Trievel RC, Shilatifard A: Regulation of H3K4 trimethylation via Cps40 (Sppl) of compass is monoubiquitination independent: implication for a Phe/Tyr switch by the catalytic domain of Set1. Mol Cell Biol 2009;29:3478-3486.

- 33 Schneider J, Wood A, Lee JS, Schuster R, Dueker J, Maguire C, Swanson SK, Florens L, Washburn MP, Shilatifard A: Molecular regulation of histone $\mathrm{H} 3$ trimethylation by compass and the regulation of gene expression. Mol Cell 2005;19:849-856.

-34 Steward MM, Lee JS, O'Donovan A, Wyatt M, Bernstein BE, Shilatifard A: Molecular regulation of $\mathrm{H} 3 \mathrm{~K} 4$ trimethylation by ASH2L, a shared subunit of MLL complexes. Nat Struct Mol Biol 2006;13:852-854

- 35 Wysocka J, Swigut T, Milne TA, Dou Y, Zhang X, Burlingame AL, Roeder RG, Brivanlou AH, Allis CD: WDR5 associates with histone $\mathrm{H} 3$ methylated at $\mathrm{K} 4$ and is essential for H3 K4 methylation and vertebrate development. Cell 2005;121:859-872.

-36 Ruthenburg AJ, Wang W, Graybosch DM, Li $\mathrm{H}$, Allis CD, Patel DJ, Verdine GL: Histone $\mathrm{H} 3$ recognition and presentation by the WDR5 module of the MLL1 complex. Nat Struct Mol Biol 2006;13:704-712.

- 37 Sims RJ 3rd, Reinberg D: Histone H3 Lys 4 methylation: caught in a bind? Genes Dev 2006;20:2779-2786.

38 Russo JJ, Bohenzky RA, Chien MC, Chen J, Yan M, Maddalena D, Parry JP, Peruzzi D, Edelman IS, Chang Y, Moore PS: Nucleotide sequence of the Kaposi sarcoma-associated herpesvirus (HHV8). Proc Natl Acad Sci USA 1996;93:14862-14867.
39 Parravicini C, Chandran B, Corbellino M, Berti E, Paulli M, Moore PS, Chang Y: Differential viral protein expression in Kaposi's sarcoma-associated herpesvirus-infected diseases: Kaposi's sarcoma, primary effusion lymphoma, and multicentric castleman's disease. Am J Pathol 2000;156:743-749.

40 Decker LL, Shankar P, Khan G, Freeman RB, Dezube BJ, Lieberman J, Thorley-Lawson DA: The Kaposi sarcoma-associated herpesvirus (KSHV) is present as an intact latent genome in KS tissue but replicates in the peripheral blood mononuclear cells of KS patients. J Exp Med 1996;184:283-288.

41 Zhong W, Wang H, Herndier B, Ganem D: Restricted expression of Kaposi sarcoma-associated herpesvirus (human herpesvirus 8) genes in Kaposi sarcoma. Proc Natl Acad Sci USA 1996;93:6641-6646.

42 Deng H, Liang Y, Sun R: Regulation of KSHV lytic gene expression. Curr Top Microbiol Immunol 2007;312:157-183.

43 Wei Y, Mizzen CA, Cook RG, Gorovsky MA, Allis CD: Phosphorylation of histone $\mathrm{H} 3$ at serine 10 is correlated with chromosome condensation during mitosis and meiosis in tetrahymena. Proc Natl Acad Sci USA 1998; 95:7480-7484.

44 Wei Y, Yu L, Bowen J, Gorovsky MA, Allis CD: Phosphorylation of histone $\mathrm{H} 3$ is re quired for proper chromosome condensation and segregation. Cell 1999;97:99-109.

$>45$ Lacoste V, de la Fuente C, Kashanchi F, Pumfery A: Kaposi's sarcoma-associated herpesvirus immediate early gene activity. Front Biosci 2004;9:2245-2272.

46 Xu Y, Rodriguez-Huete A, Pari GS: Evaluation of the lytic origins of replication of Kaposi's sarcoma-associated virus/human herpesvirus 8 in the context of the viral genome. J Virol 2006;80:9905-9909.

47 Sun R, Lin SF, Gradoville L, Miller G: Polyadenylylated nuclear RNA encoded by Kaposi sarcoma-associated herpesvirus. Proc Natl Acad Sci USA 1996;93:11883-11888.

48 Song MJ, Brown HJ, Wu TT, Sun R: Transcription activation of polyadenylated nuclear RNA by RTA in human herpesvirus $8 / \mathrm{Ka}$ posi's sarcoma-associated herpesvirus. J Virol 2001;75:3129-3140.

49 Byun H, Gwack Y, Hwang S, Choe J: Kaposi’s sarcoma-associated herpesvirus open reading frame (ORF) 50 transactivates $\mathrm{K} 8$ and ORF57 promoters via heterogeneous response elements. Mol Cells 2002;14:185-191.
50 Malik P, Blackbourn DJ, Cheng MF, Hayward GS, Clements JB: Functional co-operation between the Kaposi's sarcoma-associated herpesvirus ORF57 and ORF50 regulatory proteins. J Gen Virol 2004;85:2155-2166.

-51 Ballestas ME, Chatis PA, Kaye KM: Efficient persistence of extrachromosomal KSHV DNA mediated by latency-associated nuclear antigen. Science 1999;284:641-644.

52 Cotter MA 2nd, Robertson ES: The latencyassociated nuclear antigen tethers the kaposi's sarcoma-associated herpesvirus genome to host chromosomes in body cavity-based lymphoma cells. Virology 1999;264:254264.

53 Wada T, Takagi T, Yamaguchi Y, Ferdous A, Imai T, Hirose S, Sugimoto S, Yano K, Hartzog GA, Winston F, Buratowski S, Handa H: DSIF, a novel transcription elongation factor that regulates RNA polymerase II processivity, is composed of human Spt4 and Spt5 homologs. Genes Dev 1998;12:343-356.

54 Shilatifard A: Factors regulating the transcriptional elongation activity of RNA polymerase II. FASEB J 1998;12:1437-1446.

55 Marshall NF, Price DH: Control of formation of two distinct classes of RNA polymerase II elongation complexes. Mol Cell Biol 1992;12:2078-2090.

56 Narita T, Yamaguchi Y, Yano K, Sugimoto S, Chanarat S, Wada T, Kim DK, Hasegawa J, Omori M, Inukai N, Endoh M, Yamada T, Handa H: Human transcription elongation factor NELF: identification of novel subunits and reconstitution of the functionally active complex. Mol Cell Biol 2003;23:1863-1873.

57 Yamaguchi Y, Takagi T, Wada T, Yano K, Furuya A, Sugimoto $\mathrm{S}$, Hasegawa J, Handa $\mathrm{H}$ : NELF, a multisubunit complex containing $\mathrm{RD}$, cooperates with DSIF to repress RNA polymerase II elongation. Cell 1999;97:4151.

58 Toth Z, Brulois K, Wong LY, Lee HR, Chung $B$, Jung JU: Negative elongation factor-mediated suppression of RNA polymerase II elongation of Kaposi's sarcoma-associated herpesvirus lytic gene expression. J Virol 2012; 86:9696-9707. 